\title{
Professional training on shared decision making with older adults living with neurocognitive disorders: a mixed-methods implementation study
}

Moulikatou Adouni Lawani ${ }^{1}$, Luc Côté ${ }^{2}$, Laetitia Coudert ${ }^{3}$, Michèle Morin ${ }^{4}$, Holly O. Witteman ${ }^{1,5}$, Danielle Caron ${ }^{6}$, Edeltraut Kroger ${ }^{7}$, Philippe Voyer ${ }^{8}$, Charo Rodriguez ${ }^{9}$, France Légaré ${ }^{1,10}$ and Anik M. C. Giguere ${ }^{1,5,7^{*}}$ (D)

\begin{abstract}
Background: Shared decision making with older adults living with neurocognitive disorders is challenging for primary healthcare professionals. We studied the implementation of a professional training program featuring an elearning activity on shared decision making and five Decision Boxes on the care of people with neurocognitive disorders, and measured the program's effects.

Methods: In this mixed-methods study, we recruited healthcare professionals in family medicine clinics and homecare settings in the Quebec City area (Canada). The professionals signed up for training as a continuing professional development activity and answered an online survey before and after training to assess their knowledge, and intention to adopt shared decision making. We recorded healthcare professionals' access to each training component, and conducted telephone interviews with a purposeful sample of extreme cases: half had completed training and the other half had not. We performed bivariate analyses with the survey data and a thematic qualitative analysis of the interviews, as per the theory of planned behaviour.

Results: Of the 47 participating healthcare professionals, 31 (66\%) completed at least one training component. Several factors restricted participation, including lack of time, training fragmentation into several components, poor adaptation of training to specific professions, and technical/logistical barriers. Ease of access, ease of use, the usefulness of training content and the availability of training credits fostered participation. Training allowed Healthcare professionals to improve their knowledge about risk communication $(p=0.02)$, and their awareness of the options $(P=0.011)$. Professionals' intention to adopt shared decision making was high before training (mean \pm $\mathrm{SD}=5.88 \pm 0.99$, scale from 1 to 7 , with 7 high) and remained high thereafter (5.94 \pm 0.9$)$.

\footnotetext{
* Correspondence: anik.giguere@fmed.ulaval.ca

'Department of Family Medicine and Emergency Medicine, Laval University,

Pavillon Ferdinand-Vandry, room 2881, 1050 avenue de la Médecine,

Quebec, QC GIV OA6, Canada

${ }^{5}$ VITAM Research Centre on Sustainable Health, Pavillon Landry-Poulin, Door

A-1-2, 2nd floor, Room 2416, 2525 Chemin de la Canardière, Québec, QC G1J

OA4, Canada

Full list of author information is available at the end of the article
}

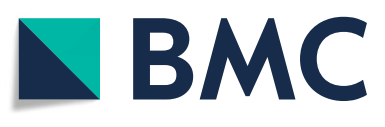

(c) The Author(s). 2020 Open Access This article is licensed under a Creative Commons Attribution 4.0 International License, which permits use, sharing, adaptation, distribution and reproduction in any medium or format, as long as you give appropriate credit to the original author(s) and the source, provide a link to the Creative Commons licence, and indicate if changes were made. The images or other third party material in this article are included in the article's Creative Commons licence, unless indicated otherwise in a credit line to the material. If material is not included in the article's Creative Commons licence and your intended use is not permitted by statutory regulation or exceeds the permitted use, you will need to obtain permission directly from the copyright holder. To view a copy of this licence, visit http://creativecommons.org/licenses/by/4.0/ The Creative Commons Public Domain Dedication waiver (http://creativecommons.org/publicdomain/zero/1.0/) applies to the data made available in this article, unless otherwise stated in a credit line to the data. 
(Continued from previous page)

Conclusions: The results of this study will allow modifying the training program to improve participation rates and, ultimately, uptake of meaningful shared decision making with patients living with neurocognitive disorders.

Keywords: Primary care, Shared decision-making, E-learning, Distance learning, Evidence summary, Decision support technology, Decision boxes, Continued professional development, Aging, Dementia

\section{Background}

The care of older adults living with neurocognitive disorders (NCDs) requires making difficult decisions. For instance, the disabling and multi-morbid nature of this condition involves selecting services to reorganize daily life, choosing pharmaceutical or non-pharmaceutical treatments, and preparing advanced care plans and directives. Because there are generally several acceptable options for these decisions, decision making should consider the experiences, preferences, and values of the older adult living with NCDs and their family or friend caregiver. The shared decision-making (SDM) process is ideal for guiding decision making in this context, as it relies on a discussion among all parties to balance evidence-based healthcare information, the expertise of the healthcare professional $(\mathrm{HCP})$, and the experiential knowledge, values, and preferences of the person living with NCDs and their family/friend caregivers. A large systematic review recently established that SDM helps improve patients' knowledge of the options, congruency between their values and care choice, comfort with the decision, and engagement in decision making [1]; however adoption of SDM by HCPs in their routine practice is still suboptimal [2].

SDM implementation in the context of caring for older adults with NCDs remains largely unexplored. Implementation studies have been conducted in nursing home residents living with NCDs [3, 4], and a single study has been completed to date to implement SDM among the interprofessional care team, family/friend caregivers, and community-based older adults living with NCDs, for housing decisions [5]. Decision making in the context of NCDs is particularly challenging, as decisions are often emotionally laden [6] and complicated by the disease, ethical and legal dilemmas, and the presence of multiple stakeholders [7]. As a result, older adults living with NCDs are typically excluded prematurely from decision making [7]. Hence, there is a need for studies to inform the implementation of professional training and patient/ caregiver decision aids to support SDM among community-based older adults living with NCDs, their caregivers, and interprofessional teams.

A recent systematic review of 15 studies highlights a lack of evidence on the effectiveness of different types of interventions to improve SDM adoption among HCPs, such as educational meetings, educational material, educational outreach visits, and reminders [8]. Furthermore, although an environmental scan described 168 validated professional training programs in SDM [9], the assessment of their effects and implementation is heterogeneous, and there is still a lack of evidence on the best practices to develop, implement, and assess these training programs [10]. Participation in continuing professional development (CPD) strategies is challenging for $\mathrm{HCPs}$, especially for those who work in remote areas and need to travel long distances to take part [11, 12]. A recent systematic review suggests that remote online training, or e-learning, could be more accessible-and equally effective-as face-to-face training [13].

We thus set out to study the factors influencing participation in a professional e-learning program on SDM comprising an e-learning activity and five Decision Boxes on the care of older adults with NCDs, by addressing three specific questions:

1. What is the level of participation of HCPs in the various components of the program?

2. Which factors influence HCPs participation in the program?

3. What are the effects of the program on HCPs' knowledge about and intention to adopt SDM with these patients?

\section{Methods \\ Description of the training program}

This professional training program included (1) a selfdirected e-learning activity on SDM, lasting about $1 \mathrm{~h}$, that participants could complete in several sittings at their work location or at home; and (2) five evidence summaries, or Decision Boxes (DBs), to support decision making at the point of care.

The generic e-learning activity included four successive training modules that aimed to 1) explain SDM and its implementation in daily practice; 2) describe strategies for determining patients' values and preferences; 3 ) describe strategies for communicating probabilities to patients; and 4) explain how to incorporate SDM into clinical encounters with patients. The minimum duration of each module was respectively 9 min for Module \#1; 20 min for Module \#2; 6 min for Module \#3; and 28 min for Module \#4. The design of this activity was based 
Table 1 Decision Box titles and level of participants' interest for each title

\begin{tabular}{lll}
\hline $\begin{array}{l}\text { Distribution } \\
\text { order }\end{array}$ & Decision Box title & $\begin{array}{l}\text { Interest in the title, on } \\
\text { a scale from } 0 \text { to } 100 \text { with } 100 \text { high } \\
\text { Mean (SD); }(n=47)\end{array}$ \\
\hline 1 & $\begin{array}{l}\text { Choosing a non-pharmacological treatment to manage agitation, aggression, or psychotic } \\
\text { symptoms }\end{array}$ & $87(11)$ \\
2 & Choosing an option to maintain quality of life & $85(13)$ \\
3 & Choosing a support option to decrease caregiver burden & $80(18)$ \\
4 & Deciding whether or not to stop driving following diagnosis & $78(30)$ \\
\hline
\end{tabular}

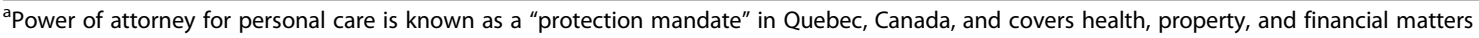

on our team's earlier work on CPD training to support SDM for acute respiratory tract infections [14].

The series of five evidence summaries described the options available to older adults living with NCDs who are faced with five important and frequent decisions that we identified in an earlier study (Table 1) [15]. We designed these evidence summaries as Decision Boxes (DBs), which are meant to provide stakeholders with evidence in a format supportive of SDM (i.e., one that avoids biasing decision making by concisely setting out the pros and cons of all available options, in absolute risks) $[16,17]$.

Professionals who completed training (arbitrarily defined as completing the four e-learning modules and any one of the five $\mathrm{DBs}$ ), were entitled to training credits. Participation was otherwise voluntary, since we offered no other incentives.

In parallel with this professional training program, we also designed and evaluated patient decision aids for each of these decisions, a project that is reported elsewhere [18].

\section{Study design}

In this explanatory, sequential, mixed-method study, we assessed participation in each training component using quantitative access data (Fig. 1). We also asked participants to complete quantitative questionnaires before and after training, to assess the effects of the




training program on their knowledge and intention. Our hypothesis was participants' knowledge and intention would increase after training. Then, we sought to understand the factors influencing participation using semi-structured individual interviews with a subset of participants selected based on the results of the quantitative phase.

We originally planned this study as a clustered randomized trial that is described elsewhere [19]. In short, this study aimed to assess the effectiveness of the professional training program in increasing the empowerment of older adults living with NCDs and their caregivers to make health-related decisions. Unfortunately, we experienced low patient recruitment rates and rather studied the implementation of this training program and its effectiveness in influencing variables at the HCP level.

\section{Participants}

We recruited a convenience sample HCPs from various professions (e.g., family physicians, nurses, and social workers) who practiced in family medicine clinics and homecare services in the province of Quebec, Canada. We presented the study to the HCPs during one of their regularly scheduled team meetings. Those who agreed to participate signed an informed consent form, completed a study entry questionnaire on their sociodemographic and professional characteristics (age, gender, profession, years of practice, city size), and responded to a question to assess their interest in each DB topic, on a slider scale ranging from 0 to 100 , with 100 high.

\section{Implementation strategy}

The participants received an email with the access codes to the e-learning activity, and to the DB. After this first email, we sent them four more emails, one every 2 weeks, to give them access to each $\mathrm{DB}$ and to remind them of the e-learning activity. Overall, the participants had access to the training program from February 2018 to May 2018. The DBs were distributed in the same order to all participants, starting with the topic that they rated as the most interesting, on average, and then in decreasing order of interest (Table 1).

\section{Quantitative data collection \\ Survey}

The study participants completed an online survey before and after the e-learning activity. The survey included 27 questions: (A) one question on their prior training in SDM; (B) one question inspired by the Ottawa Decision Support Framework to assess their knowledge about SDM [20]; (C) one question to assess their knowledge about risk communication; (D) two questions with case base scenarios for each DB topic, to assess participants' perceived awareness of the available options and awareness of the options; (E) eight questions, including case-based scenarios, to assess clinical knowledge relative to the care of older adults living with NCDs; (F) five questions to evaluate participants' intention to use SDM with their next patient facing a preference-sensitive decision, and the determinants of this intention (attitude, beliefs about capabilities, moral norm, and social influence), using a brief 5 -item version of the CPD-REACTION [21]; (G) eight questions to assess perceptions of their ability to adopt SDM using the novel IcanSDM scale [22]; and $(\mathrm{H})$ one question to assess their preferred role in decision-making [23].

\section{Access data}

The website that supported e-learning activity allowed recording participants' access to each training component, as well as the time spent on each module in the elearning activity. We were also able to record participants' access to the DBs when they answered a questionnaire about their experience using the tool, the results of which are reported elsewhere [24].

\section{Qualitative data collection Selection of a participant subsample}

We aimed to recruit a subsample of 16 people from among the participants, to interview them about the factors that encouraged or restricted their participation in training. We estimated that this sample size should allow saturation since the sample was relatively homogenous and the questions discussed were straightforward and practical. Among the 16 people, we planned to recruit eight who had fully participated in training and eight who had not. To recruit people who had participated in training, we had a question in the survey that they completed after training, asking their permission to contact them by phone for a 30-min individual interview. We recruited people who had not participated by email.

\section{Procedure}

We conducted the individual phone interviews (roughly 30 min in length) 1 month after participants had completed the professional training program. We used a semi-structured interview guide to elicit (1) their attitude towards the training program, and (2) their beliefs about their capabilities to complete the training program. The interview guide was based on the Theory of Planned Behaviour [25], according to which a behaviour may be predicted by a person's intention (motivation) to adopt it, and a person's intention may, in turn, be predicted by several determinants, including belief about consequences, social influence, and beliefs about capabilities. We also asked a few questions to explore how they used what they learned through the program in their encounters with patients. 
We recorded the interviews using audio-digital recorders, and transcribed the discussions verbatim.

\section{Analyses}

We completed descriptive analyses of all quantitative data. We used simple logistic regressions to identify the factors influencing completion of the training program. To this end, we first performed univariate between completion and each of the potential factors (sociodemographic and professional characteristics, prior training in SDM, interest for each of the DB topic). We then tested a simple logistic regression model comprising all the factors that demonstrated a significant effect on completion. All quantitative statistical analyses were conducted using the SAS statistical package (SAS Institute Inc), and bilateral statistical tests were performed at a significance level of 0.05 .

We also performed bivariate analyses to compare questionnaire responses before and after the training program. In addition, we used student-dependent paired T-tests to compare mean scores and the Fisher test to compare proportions before and after training.

For qualitative data, three researchers independently conducted a thematic content analysis using an deductive approach, initially based on the individual factors described by the Theory of Planned Behaviour [25], then on the emerging themes of the discussions. The analyses aimed to describe the factors encouraging and restricting participation in the training program.

We then explored the qualitative results to discover any confirmation, contradiction, cross-validation, or corroboration of the quantitative results [26]. Drawing on the various sources, the research team met to suggest strategies to improve the training program and its implementation.

We obtained ethical approval for this project from the ethics review board of the Ministre de la santé et des Services Sociaux (reference CCER15-16-05) and the Centre Hospitalier Universitaire de Québec (reference 20162521). All participants signed consent forms for the study.

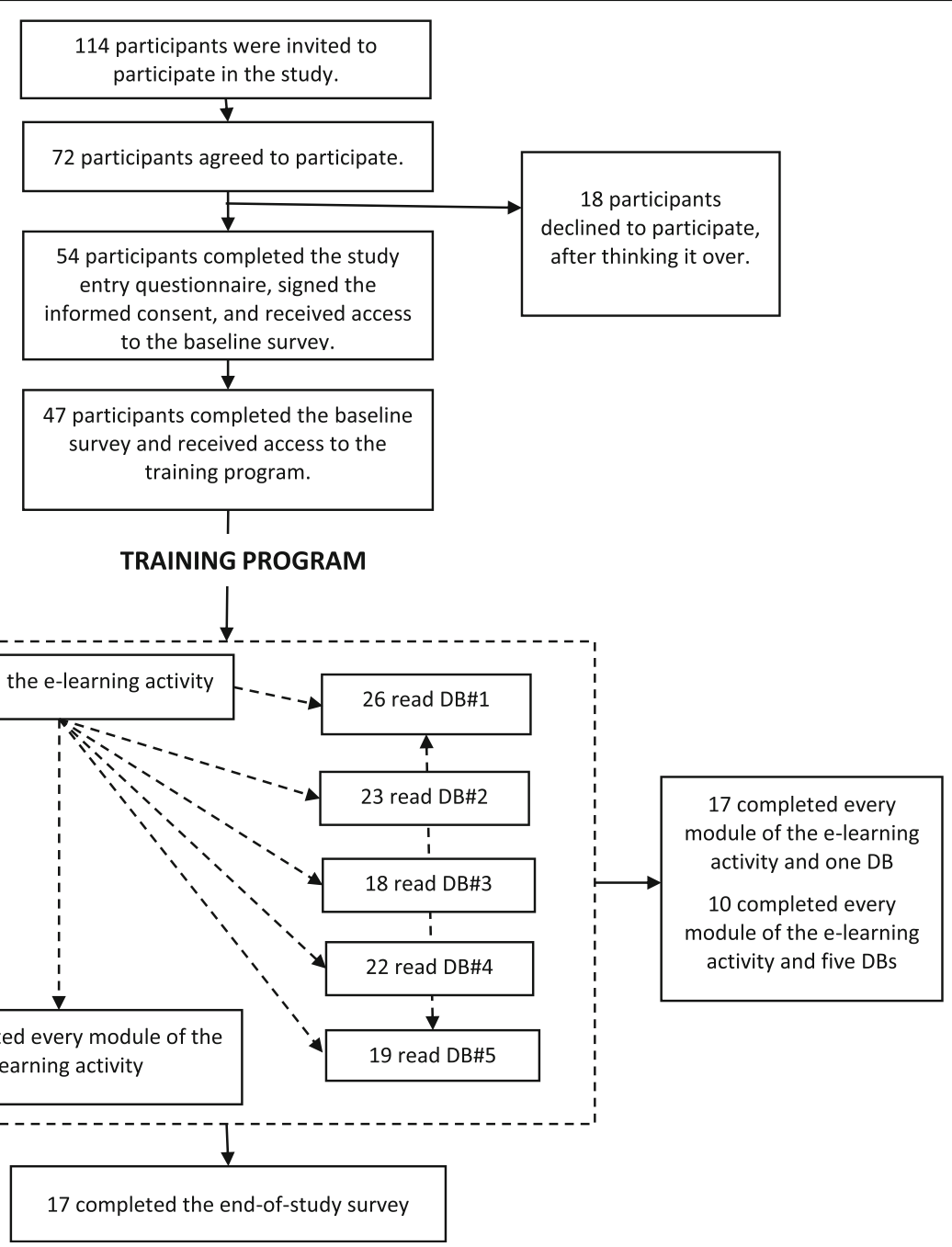

Fig. 2 Flow of participants (see Table 1 for DB titles) 
Table 2 Characteristics of study participants

\begin{tabular}{|c|c|c|}
\hline \multirow{2}{*}{$\begin{array}{l}\text { Participant } \\
\text { Characteristics }\end{array}$} & \multicolumn{2}{|c|}{ Frequency (Total $\boldsymbol{N}=47$ ) } \\
\hline & $\bar{n}$ & $\%$ \\
\hline \multicolumn{3}{|l|}{${ }_{\text {Age (years) }}{ }^{a}$} \\
\hline Under 30 & 7 & 15.2 \\
\hline $30-39$ & 15 & 32.6 \\
\hline $40-49$ & 15 & 32.6 \\
\hline $50-59$ & 8 & 17.4 \\
\hline $60-69$ & 1 & 2.2 \\
\hline \multicolumn{3}{|l|}{ Gender } \\
\hline Female & 39 & 83.0 \\
\hline Male & 8 & 17.0 \\
\hline \multicolumn{3}{|l|}{ Profession } \\
\hline Physician & 17 & 36.2 \\
\hline Nurse & 10 & 21.3 \\
\hline Social worker & 10 & 21.3 \\
\hline Occupational therapist & 6 & 12.8 \\
\hline Nursing assistant & 1 & 2.1 \\
\hline Dietician & 1 & 2.1 \\
\hline Pharmacist & 1 & 2.1 \\
\hline Physiotherapist & 1 & 2.1 \\
\hline \multicolumn{3}{|c|}{ City size where practice located ${ }^{\mathbf{b}}$} \\
\hline Rural area & 0 & 0.0 \\
\hline Small city & 6 & 12.8 \\
\hline Mid-size city & 0 & 0.00 \\
\hline Large city & 41 & 87.2 \\
\hline \multicolumn{3}{|l|}{ Years of practice ${ }^{c}$} \\
\hline$<10$ & 18 & 38.3 \\
\hline $10-19$ & 11 & 23.4 \\
\hline $20-29$ & 12 & 25.5 \\
\hline $30-39$ & 3 & 6.4 \\
\hline Do not recall & 3 & 6.4 \\
\hline \multicolumn{3}{|c|}{ Received prior SDM training } \\
\hline Yes & 9 & 19.2 \\
\hline No & 38 & 80.9 \\
\hline
\end{tabular}

${ }^{\mathrm{a} O n e}$ missing data for age

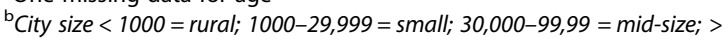
$100,000=$ large (Statistics Canada, 2011)

${ }^{c}$ Years of practice $=$ year of data collection (2018) - year practice license was granted

\section{Results}

\section{Participants}

Of the 114 HCPs invited to participate, 72 (63\%) accepted (Fig. 2). Eighteen left the study before signing the informed consent and completing the study entry questionnaire. Of the 54 participants who signed the informed consent and completed the study entry questionnaire, 47 completed the baseline survey and received access to training. Of these 47 people, 17 (36\%) completed the final survey after training.

Most of the 47 participants who completed the baseline survey were women (83\%) (Table 2). They represented several professions, but most were physicians (36\%), nurses (21\%), or social workers (21\%). Most of them (81\%) had never had any training in SDM. They reported a mean interest in the topics covered in the DBs of $80 \%$ ( \pm SD 14\%); they were most interested in DB\#1 (Non-pharmacological treatment to manage agitation, aggression, or psychotic symptoms) (mean interest $=87 \pm \mathrm{SD} 11 \%$ ) and least interested in $\mathrm{DB} \# 5$ (Deciding whether or not to prepare a power of attorney for personal care) (mean interest $=67 \pm$ SD 32\%) (Table 1).

\section{Level of participation in the training program}

Of the 47 participants who completed the baseline survey, 17 (36\%) completed the four modules of the elearning activity in addition to reviewing a minimum of one DB; 10 (21\%) completed the four e-learning modules and reviewed five DBs (Fig. 2). If we consider the DBs exclusively, 26 of the 47 participants $(55 \%)$ reviewed at least one DB.

Completion time of the entire e-learning activity ranged from $40 \mathrm{~min}$ to $9 \mathrm{~h}$, for an average duration of $57 \mathrm{~min}$. Some participants spent as long as $5 \mathrm{~h}$ on the introduction, while $68 \%$ of the 47 participants spent less than $30 \mathrm{~min}$ on it. These estimates could, however, reflect the time during which people were connected to the activity without being actively engaged in doing the training.

Of the 20 participants who completed all the modules of the e-learning activity, four took $2 \mathrm{~h} 30$ to complete it (20\%), and 16 took less than $2 \mathrm{~h}$ (from $47 \mathrm{~min}$ to $1 \mathrm{~h} 52$ ). The average time to complete the modules $1,2,3$, and 4 were respectively, $29 \mathrm{~min}( \pm \mathrm{SD}$ of $23 \mathrm{~min}$; range 5-95 $\mathrm{min}), 38 \mathrm{~min} \mathrm{(} \pm 68 \mathrm{~min}$; range of $4-255 \mathrm{~min}), 6 \mathrm{~min}( \pm 4$ $\mathrm{min}$; range of $2-19 \mathrm{~min})$, and $17 \mathrm{~min}( \pm 10 \mathrm{~min}$; range of 6-44 min).

Of the 11 participants who accessed the e-learning activity and did not complete all the modules, nine stopped after less than 5 min on the Introduction or on Module 1 (82\%), and two completed the first two modules only, in about $1 \mathrm{~h}(18 \%)$.

The logistic regression to describe the factors influencing participation in the training program gave no statistically significant factor explaining completion.

\section{Interview findings: factors influencing participation in the training program}

We recruited and interviewed 11 participants instead of the 16 planned, since we reached data saturation in the 
last interviews conducted when we failed to record any new emerging theme [27]. Of these 11 participants, six had completed all the modules of the e-learning activity and one DB, and five had not.

These interviews allowed us to identify several factors encouraging or restricting participation in training, with regard to participant attitudes and beliefs about their capabilities. The study of these factors then led us to pinpoint specific strategies for improving the training program and its implementation. These findings are described in the next paragraphs.

\section{Factors encouraging participation}

Both the participants who fully completed the training program, and those who partially completed it, had general positive attitudes towards it (Table 3). They perceived the training program as useful for learning about SDM, for improving their management of the problems faced by older adults living with NCDs, and for improving their communication with them. Participants especially appreciated the fact that training allowed them to become aware of the DBs and other patient decision aids. Some participants mentioned that the DBs covered topics of interest for practice, and that they helped meet their clinical needs. Several participants also pointed to the usefulness of the DBs because they presented various interventions, with their pros and cons. A number of participants mentioned how completing the program trained them to communicate understandable information on all the options to patients, and to provide them guidance.

The participants reported several factors encouraging their participation with regard to their beliefs about their capabilities to participate. Most mentioned ease of access to the training program as a factor encouraging their participation. They mentioned that it was easy to do, as it was concise and clear, and they appreciated the short modules of the e-learning activity that made it easier to retrieve information. They also valued the DBs from a practical point of view, noting that accessing the information in the DBs is quick due to their brevity, the standardized presentation of information, and the availability of different DBs for each clinical situation. They further appreciated that DBs were printable, and mentioned their convenience as a source of information for patients/caregivers after the consultation. Participants also appreciated that completing training did not require any prerequisites. They also found that the training program was easy-to-understand and visually appealing, and they appreciated that it provided practical training. The participants reported that they found the DB well explained and that they offered practical guidance. One participant also mentioned how learning was applicable to other clinical situations. Participants also mentioned that extrinsic sources encouraged their participation, in particular the email follow-ups and the associated continuing education credits.

The participants made several suggestions to improve participation to the training program, the most important of which was to shorten training and integrate it formally into participants' working schedules. Some people also mentioned that it would be desirable to be able to adjust the speed of the narration. Regarding implementation, the participants suggested extending dissemination of the DBs, especially to employers and decisionmakers.

\section{Factors restricting participation in the training program}

All of the factors mentioned by participants as limiting their participation were aspects of their beliefs about their capabilities to participate (Table 4). The factor most frequently reported was their lack of time, or the time required. Participants explained how it was generally difficult for them to find time to complete training. They also mentioned that time required to adopt the tools may be longer for professionals lacking experience in the topic. A number mentioned that the period selected to distribute the program was suboptimal because it was a particularly busy time.

Among the other factors limiting participation, we identified certain disadvantages of the training components themselves, technical or logistical barriers, social barriers, and difficulties in using DBs. For example, some participants reported that spacing out the training elements for several weeks made the training more difficult to follow. The technical barriers reported consisted in difficulties accessing the Internet access or navigating the website. Participants also indicated that their colleagues and employer influenced their determination to complete the training. Lastly, participants indicated that the use of DBs entailed certain costs and required adapting them to each patient individually before integrating them formally into their practice.

\section{Strategies for improving the training program and its implementation}

Based on the factors identified that encouraged and restricted participation in training, on the strategies proposed by participants themselves, on authors' experience and on scientific evidence, we identified a set of strategies for improving the learning components used in the training program, as well as strategies to improve its implementation (Table 5). A few of the proposed strategies address time constraints, such as officially incorporating training into the participant's schedule and adapting training length to individual needs and experience. Other proposed strategies address the inconvenience of 


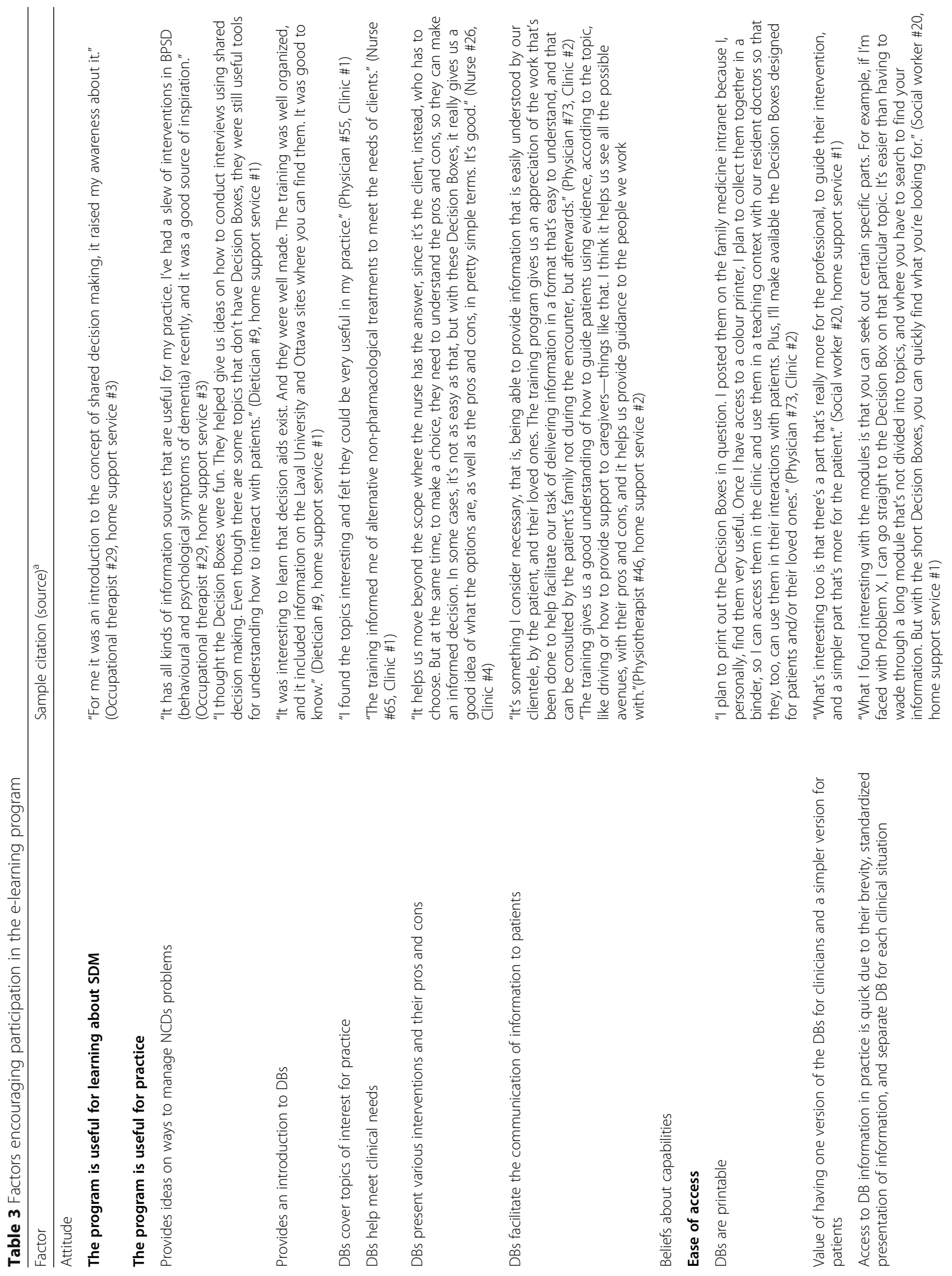




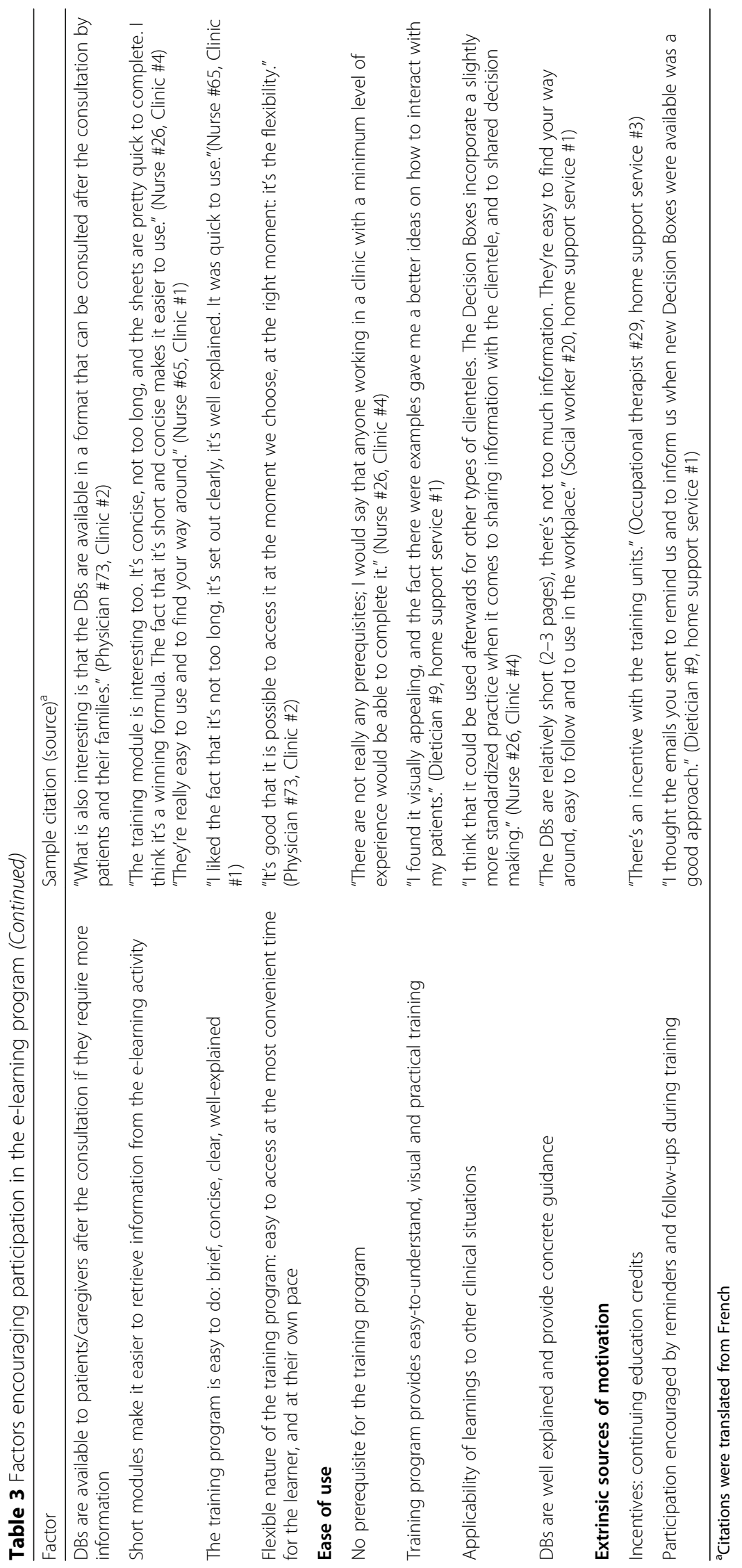




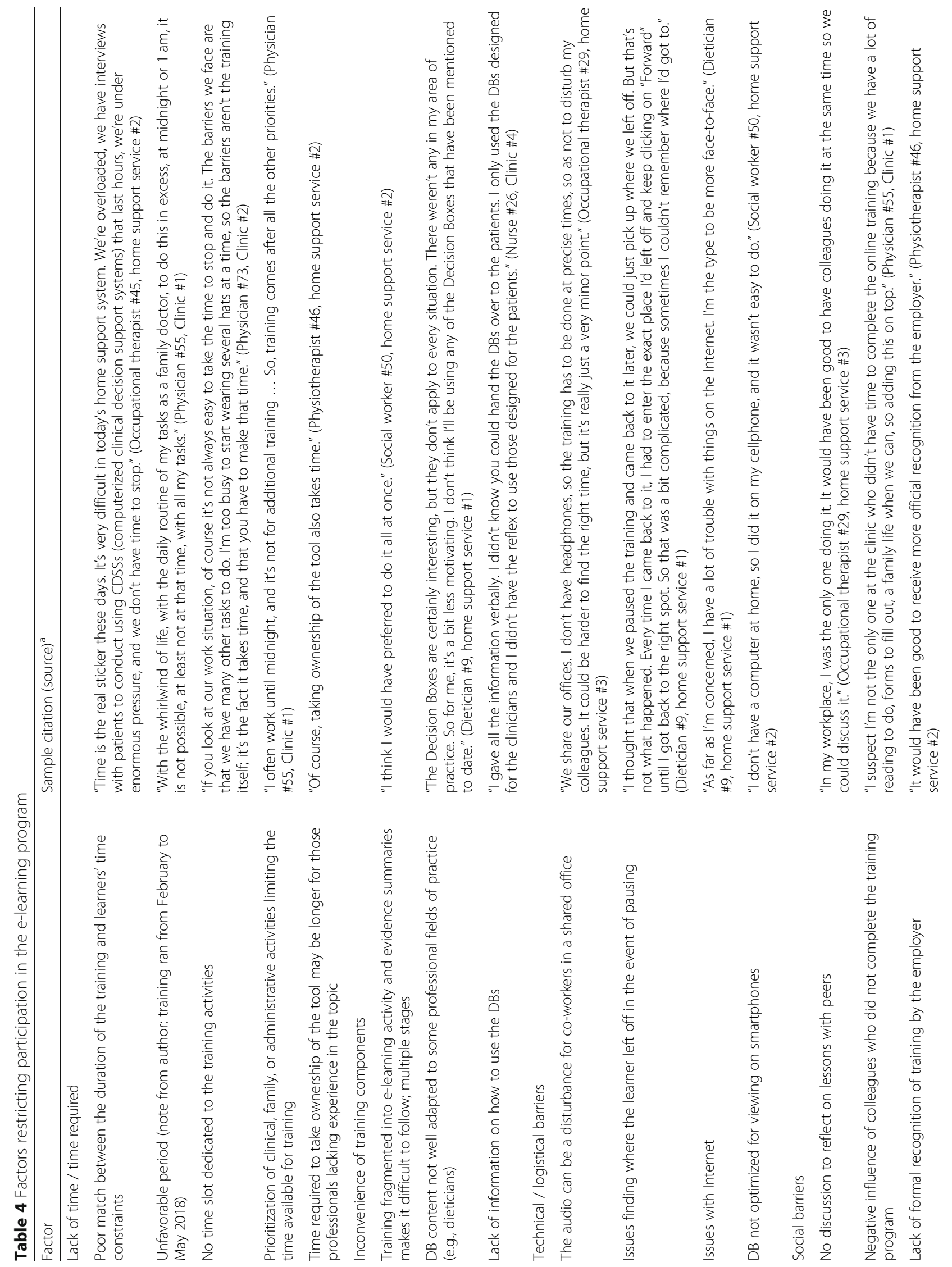


Lawani et al. BMC Medical Informatics and Decision Making

(2020) 20:189

Page 11 of 17

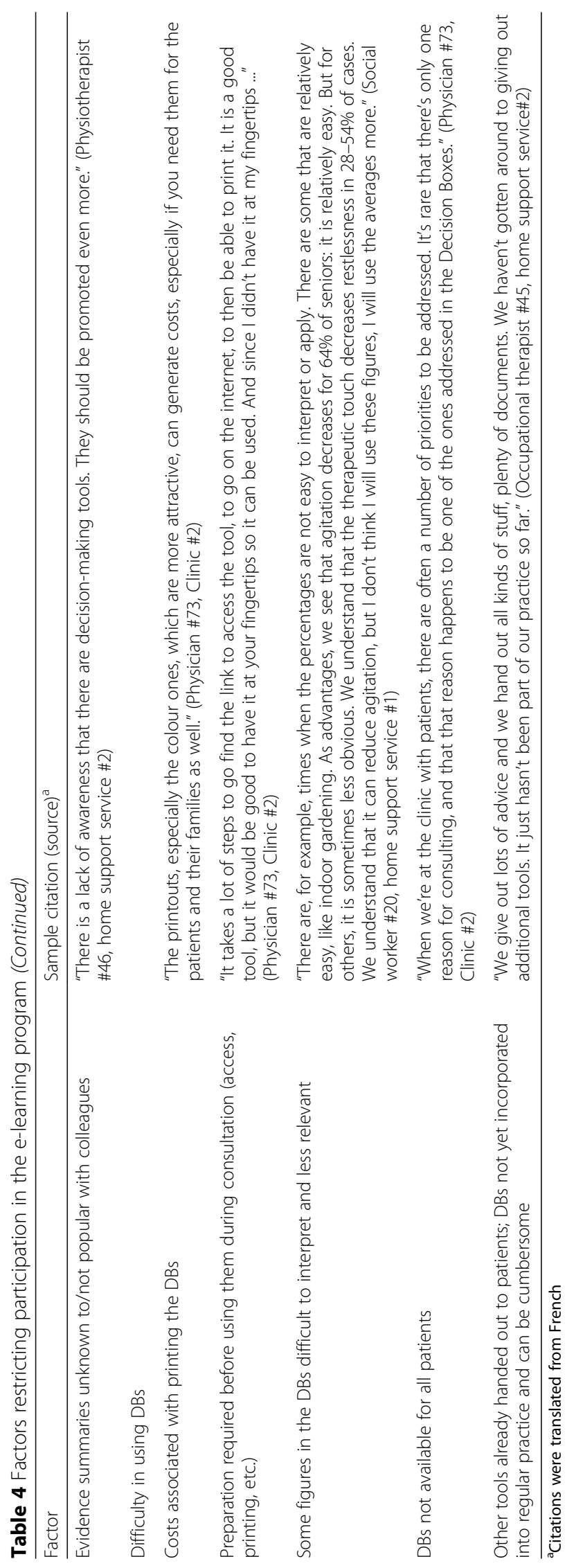


Table 5 Strategies to improve training program on shared decision making with older adults with neurocognitive disorders Strategy

To improve learning modalities

Offer the option of receiving the DBs in a single block rather than in sections.

Make the online activity available in print format for regions with limited Internet access.

Subdivide the longer modules.

Use podcasts.

Give participants the option of skipping the modules on topics they are already familiar with.

Clarify the availability of the tools throughout the training program, and promote their potential as a teaching aid for interns.

Create the possibility for learners to adjust the speed of the narration in the videos.

Make headphones available to learners in shared workspaces.

Make it easier to pick up training again after pausing.

Include a user guide for learners who are less tech-savvy.

To improve implementation

Include targeted messages to help promote the training program:

- By clarifying learners' preferred objectives (understanding SDM, learning about the tools, understanding the evidence about the different interventions)

- By highlighting the clinical issues covered by the DBs, since they are practice-oriented

- By promoting the usefulness of DBs to communicate information to patients

Maintain training credits as a source of motivation, enhance them if possible, and add other possible sources of motivation.

Make the training program shorter.

Officially incorporate the training into the participant's schedule by negotiating with immediate superior.

Provide training at a more convenient time of the year, e.g., in summer.

Adapt training length to individual needs and experience.

Make DBs easier to access:

- Facilitate patients' access to online DBs, e.g., by giving them the website address

- Create direct access links to the DBs in the EMR (Electronic Medical Record)

- Create direct access links to the DBs and the e-learning activity directly on clinic websites

- Offer colour printed versions (budget for them) or equip offices with colour printers

Incorporate short modules specific to each clinical intervention field.

Create DBs for all of the themes addressed in clinical encounters, and expand the practice areas covered.

Offer learners the chance to choose the DBs they wish to review, at the beginning of the training program.

In the online activity, present examples, clinical cases, or role-plays relating to various scopes of professional practice.

Simplify the data presented in the DBs.

In the online activity, explain how to present the wide confidence intervals associated with effect estimates.

Promote the tools with decision makers and employers (nursing or multidisciplinary department heads, professional bodies, universities), via webinar, for example.

Address the barriers mentioned during the learning program with presentations and credited workshops, in collaboration with officially recognized public authorities.

To improve dissemination of the tools, make them available in clinics, health institutes, libraries, and other public places.

Promote the option of doing the training as a group.

Offer incentives to participate, in the form of gifts, money, or meals.

Promote shared decision making in the population and directly support patients and their caregivers in participating to the clinical decision making process.

Promote shared decision making at level of the government. 
Table 6 Effects of the training program among participants who completed the survey before and after training

\begin{tabular}{|c|c|c|c|c|}
\hline Outcome & & $\begin{array}{l}\text { Before } \\
\text { training }\end{array}$ & $\begin{array}{l}\text { After } \\
\text { training }\end{array}$ & $P$-value \\
\hline \multicolumn{5}{|l|}{ Knowledge } \\
\hline Knowledge about SDM & Mean score (SD) (scale 1-5, with 5 high) & $4.2(1.33)$ & $3.9(1,45)$ & 0.31 \\
\hline Knowledge about risk communication & $\begin{array}{l}\text { Number of people with correct answers, } \\
\mathrm{n}(\%)\end{array}$ & $5(29.4 \%)$ & $9(52.9 \%)$ & 0.02 \\
\hline Perceived awareness of the options (3/5 Decision Boxes) & Mean score (SD) (scale 1-5, with 5 high) & $3.0(0.78)$ & $3.9(0.56)$ & 0.0006 \\
\hline Awareness of the options (3/5 Decision Boxes) & Mean proportion of correct answers (SD) & $\begin{array}{l}16.7 \% \\
(10.9 \%)\end{array}$ & $\begin{array}{l}42.2 \% \\
(32.6 \%)\end{array}$ & 0.0011 \\
\hline \multicolumn{5}{|l|}{ Clinical knowledge } \\
\hline Deprescribing antipsychotics & $\begin{array}{l}\text { Number of people with correct answers, } \\
\mathrm{n}(\%)\end{array}$ & $0(0.0 \%)$ & $4(23.5 \%)$ & 0.78 \\
\hline Impacts of stopping driving & Mean (SD) (scale 0-5, with 5 high) & $2.0(1.2)$ & $4.1(1.3)$ & 0.0004 \\
\hline Strategies to communicate about stopping driving & Mean proportion of correct answers (SD) & $\begin{array}{l}20.0 \% \\
(18.7 \%)\end{array}$ & $\begin{array}{l}25.9 \% \\
(22.1 \%)\end{array}$ & 0.07 \\
\hline Risk factors for caregiver burden & Mean (SD) (scale 0-4, with 4 high) & $3.0(1.0)$ & $3.2(1.1)$ & $>>1.000$ \\
\hline $\begin{array}{l}\text { Awareness of the information to provide patients to reflect on the Power } \\
\text { of attorney }\end{array}$ & Mean (SD) (scale 0-4, with 4 high) & $2.7(1.1)$ & $2.6(0.8)$ & 0.72 \\
\hline Characteristics of the power of attorney & Mean (SD) (scale 0-4, with 4 high) & $2.6(1.1)$ & $3.3(0.6)$ & 0.082 \\
\hline Elements to check before recommending a treatment to a vulnerable senior & Mean proportion of correct answers (SD) & $\begin{array}{l}32.4 \% \\
(30.3 \%)\end{array}$ & $\begin{array}{l}35.3 \% \\
(29.4 \%)\end{array}$ & 0.79 \\
\hline Intention to adopt SDM & $\begin{array}{l}\text { Mean score (SD) (scale 1-7, with } 7 \\
\text { indicating high intention) }\end{array}$ & $5.88(0.99)$ & $\begin{array}{l}5.94 \\
(0.90)\end{array}$ & 0.83 \\
\hline Perceived ability to adopt SDM (IcanSDM) & $\begin{array}{l}\text { Mean score (SD) (scale 1-10, with } 10 \\
\text { indicating high ability) }\end{array}$ & $6.54(1.58)$ & $\begin{array}{l}6.85 \\
(1.25)\end{array}$ & 0.43 \\
\hline Role preference & $\begin{array}{l}\text { Number of participants } \\
\mathrm{n}(\%)\end{array}$ & & & \\
\hline $\begin{array}{l}\text { I make the decision alone, relying on the best scientific evidence } \\
\text { available }\end{array}$ & & $0(0.0 \%)$ & $0(0.0 \%)$ & 0.82 \\
\hline I make the decision, but strongly considering the opinion of the patient & & $0(00.0 \%)$ & $3(17.7 \%)$ & \\
\hline The patient and I make the decision together equally & & $4(23.5 \%)$ & $4(23.5 \%)$ & \\
\hline The patient makes the decision, but strongly considering my opinion & & $5(29.4 \%)$ & $2(11.8 \%)$ & \\
\hline $\begin{array}{l}\text { The patient makes the decision alone, after obtaining information on } \\
\text { the best available scientific evidence }\end{array}$ & & $8(47.06)$ & $8(47.1 \%)$ & \\
\hline \multicolumn{5}{|l|}{ Self-reported use of the training material to answer questions after training } \\
\hline Yes & \multirow{3}{*}{$\begin{array}{l}\text { Proportion } \\
\mathrm{n}(\%)\end{array}$} & NA & $9(53)$ & NA \\
\hline No & & NA & $6(35)$ & NA \\
\hline No answer & & NA & $2(12)$ & NA \\
\hline
\end{tabular}

the training components, such as facilitating access to the DBs, making the online activity available in print format for regions with limited Internet access, and including a user's guide for those learners who are less Internet-savvy.

\section{Survey results: effects of the training program}

We partially confirmed our hypothesis to the effect that participants' knowledge and intention would increase between before and after training.
We did not observe any change in participants' knowledge about SDM after training (Table 6). By contrast, knowledge about risk communication statistically improved $(P=0.02)$. Moreover, we observed statistically significant improvements in HCPs' awareness $(P<0.001)$ and perceived awareness $(P<0.01)$ of the options after training. Training had variable effects on clinical knowledge, depending on the topic. Participants' level of intention to adopt SDM did not change between before and after training. Intention to adopt SDM was high at baseline, and remained high 
after training (mean before $=5.88 \pm 0.99$; after $=5.94 \pm$ 0.90 , on a scale ranging from 1 to 7 , with 7 the highest intention).

None of the determinants of intention measured through the CPD-REACTION (beliefs about capabilities, beliefs about consequences, social influence, moral norm) changed between before and after training. There was either no significant difference in participants' perceived ability to adopt SDM and in their preferred role in SDM before and after the training program. About half $(53 \%)$ the participants who completed the questionnaire after training reported having consulted the training material again after training to answer questions that came up.

The trends regarding these different variables before training were similar between participants who fully completed the training and those who partially completed the training.

\section{Integration of findings}

The interviews highlighted certain factors that help understand the low participation rates in training, and high attrition during training, such as lacking time and social support, technical and logistical barriers, and difficulties using the DBs. Although our quantitative results suggest that knowledge about SDM did not change between before and after, we observed positive attitudes towards SDM in participants who had completed it. We also note that, during the interviews, participants reported using the training material to answer questions after the training was over, and printing out and sharing the DBs with their colleagues and the residents under their supervision. Some participants also reported that they intended to integrate the DBs into their clinical and teaching practices. These findings concur with the high levels of intention to adopt SDM that we measured before and after training.

Additionally, our findings from the interviews about participants' appreciation of the usefulness, ease of access, and use of the training program converge with our quantitative results demonstrating an improvement in participants' clinical knowledge after training.

\section{Discussion}

In this mixed-method study, we described the level of participation of HCPs in a multi-component training program on SDM in the context of NCDs, and the factors influencing their participation. We found that, among those who had initially agreed to participate, only $24 \%$ (17/72) completed the training program. Qualitative interviews with HCPs revealed several factors restricting their participation, such as their lack of time to complete training and the fragmentation of training into several components. They also mentioned a number of factors that encouraged them to complete the training program, such as ease of use, the availability of continuing professional development credits, and the usefulness of content. We also found that training helped improve participants' knowledge about risk communication and clinical knowledge.

A large proportion of the participants who committed to completing the training did not even access it. The literature suggests that relevance of the topic, quality of content and the provision of CPD credits are important incentive to participate in SDM training activities [12, 28]. These factors were likely not responsible for the observed limited access to the program, as we ensured that learners had a high interest in the content of the training program, and the training earned them CPD credits. Instead, the qualitative interviews suggest that a lack of time and logistical barriers caused the observed limited access to training. Cook et al. [28] similarly concluded that time required to complete the activity is an important determinant of learners' selection of a CPD activity. Perhaps an online learning activity that would be broken into several smaller pieces would be preferable to the one-hour module we designed. Indeed, the Pew Research Centre on Journalism and Media examined 15 months' worth of the most popular news videos on YouTube and concluded that the length for optimal engagement with online videos is between 2 and 5 min [29]. A modified version of the training program could therefore reflect these numbers, with modules as short as $2 \mathrm{~min}$, to improve access.

Among the people who participated, a large proportion did not complete the training activities in their entirety, which agrees with several other reports of low retention in e-learning activities [30, 31]. We found the high dropout rates surprising, since we had tailored the training content and training component to the needs and preferences of learners [24], and our findings suggest that the learners found the training program useful and supportive of their clinical activities. High dropout rates may then be a consequence of the barriers participants mentioned in the interviews, such as lack of time, issues with Internet access, inconvenience of the training method, difficulty in using tools, or low peer and employer support. Similar barriers to physician engagement in self-directed e-learning in CPD were reported in a scoping review of 17 studies [32]. Resource requirements (including time, cost, and labour) and lack of information-technology skills were also reported as barriers to e-learning in health sciences education in a recent systematic review [33]. Additionally, research in education suggests that the learner's isolation [34] and their inability to engage autonomously and actively in the learning process [35] might be important 
determinants of their participation in self-directed elearning activities. We, however, did not assess these particular aspects in the current study. Because low completion rates of e-learning programs may undermine their effectiveness [30, 36], the factors influencing their participation should be considered and addressed by CPD developers to ensure the best possible learning outcomes.

We proposed several strategies to improve the learning modalities and implementation of the studied training program on SDM with older adults living with NCDs. The use of examples and role-plays are proven to be effective in training healthcare providers in SDM $[37,38]$. Mamary et al. [39] recommend providing a user's guide to learners who are less Internet-savvy. These authors also reported that computer training and dedicated time in the workplace for self-directed methods encouraged participation in self-directed continuing medical education. Some of the proposed strategies have been reported to support the participation of distance learners in CPD activities, such as providing access to a print version of the training material, lengthening the time available to complete training, offering individual profiles and follow-ups, proposing online collaboration, dividing modules into shorter sections, and supporting teamwork [40]. Another report suggests introducing a learning agreement between the learner and the university, offering support material, creating frequently asked questions (FAQs), using discussion boards, and monitoring learners' opinions for continuous improvement [41]. Monetary incentives have also been demonstrated to influence HCPs participation to e-learning activities [42]. Podcasts could also be considered as this technology is becoming more and more popular for CPD training and information dissemination [43].

Even if this training program allowed improving some of participants' knowledge, it did not allow increasing their intention to adopt SDM that was already high at baseline, nor their perceived capacity to adopt SDM. We also observed some improvement in clinical knowledge, but this is solely a secondary benefit of the training program that aimed at improving the adoption of SDM. Inclusion of outcomes at level of the older adults living with NCDs and their caregiver would have been required to conclude on the impact of this training program on patient care and quality of life from their own perspectives [44, 45]. However, we could not recruit enough older adults to assess whether training had actual impacts on the adoption of SDM. Studies with seniors with dementia consistently report high dropout rates both of seniors, caregivers and healthcare providers [46], and we were unsuccessful in addressing these challenges.
Trustworthiness of the findings is enhanced by our detailed description of the educational context and intervention, and by the use of multiple data sources (access data, surveys and interviews), methods (qualitative and quantitative), and researchers. Moreover, by collecting data both from the participants who completed training, and those who did not, we were able to provide an accurate picture of the factors at play. However, we did not ask feedback from participants on the qualitative data or interpretation of the data (member checking). We did not either use a control group in our quantitative evaluation of the impact of the training program on knowledge and intention, and so the results are prone to confounding bias since extraneous events or changes in context around the time of the intervention could have influenced the outcomes. The use of a non-random study sample and the high participant dropout rates may also have affected the results by introduction of selection bias. In addition, given the one-month delay between participation in the training activities and the interviews, recall bias is likely, and may have led to missing some important determinants to participation in the training program.

\section{Conclusions}

Our study allowed us to identify important improvements for the development and implementation of this training program. In a next step, we plan to modify the program and implement it in a scaling-up experiment. The proposed list of strategies to counter the factors that hinder the participation of HCPs in interventions to improve SDM may be applied to several clinical contexts. These findings may support researchers in planning interventions targeting HCPs, especially those who practice in primary care contexts and those in the care of older adults living with NCDs. More studies that focus on actual SDM adoption following the implementation of professional training are now required.

\section{Abbreviations \\ CPD: Continued Professional Development; DB: Decision Box; Min: Minutes; HCP: Healthcare provider; NCDs: Neurocognitive disorders; SDM: Shared Decision Making}

\footnotetext{
Acknowledgements

We would like to acknowledge the support received from the healthcare providers who participated in this project. We would also like to acknowledge the support of Juliette Bruneau as caregiver partner to this research project. We would like to recognize the contributions from several students, research professionals, and clinical experts who collaborated in the design of the training program: Valérie Carnovale, Michel Cauchon, Eyal Derhy, Nelia Domingues, Magalie Dumas, Emilie Fortier-Brochu, Dominique Giroux, Philippe Jacob, Edeltraut Kröger, Audrey Michaud, Elizabeth Parenteau, Johanne Senneville, Dominique Stibre, and Béatriz Valéra. We also wish to thank Jean-Sebastien Renaud for his help designing the survey, Josée Boulet for designing the tools, and Katherine Hastings for writing assistance.
} 


\section{Authors' contributions}

AMCG, MAL, and LeC planned the study, and contributed to recruit participants and collect the data. MAL conducted the statistical analyses. MAL, LC and AMCG contributed to the qualitative analyses. AMCG, FL, DC, EK, PV, CR and HOW contributed to the development of the e-learning activity. MAL, HOW, DC, EK, PV, and MM contributed to the design of the Decision Boxes. MAL and AMCG wrote the first draft of this manuscript. All the authors approved the final manuscript.

\section{Funding}

This project was funded by the Ministère de l'Économie, de l'Innovation et de I'Exportation du Québec, by the Société de Valorisation SOVAR, and by the VITAM Research Centre on Sustainable Health. We also received in-kind support from the Office of Education and Continuing Professional Development at Laval University. MAL is funded by a scholarship from the VITAM Research Centre on Sustainable Health. AMCG and HOW are each funded by a Research Scholar Junior 2 Career Development Award by the Fonds de Recherche du Québec - Santé. The study funders played no role in the study design, collection, analysis, and interpretation of data, writing of the report, or in the decision to submit the article for publication.

\section{Availability of data and materials}

The datasets used and/or analysed during the current study are available from the corresponding author on reasonable request.

\section{Ethics approval and consent to participate}

We obtained ethical approval for this project from the Ethics Review Board of the Ministre de la Santé et des Services Sociaux (reference CCER15-16-05) and the Centre Hospitalier Universitaire de Québec (reference 2016-2521). All participants signed an informed consent form for the study.

\section{Consent for publication}

Not applicable.

\section{Competing interests}

The authors declare that they have no competing interests.

\section{Author details}

'Department of Family Medicine and Emergency Medicine, Laval University, Pavillon Ferdinand-Vandry, room 2881, 1050 avenue de la Médecine, Quebec, QC G1V 0A6, Canada. 'Department of Family Medicine and Emergency Medicine, Laval University, Pavillon Ferdinand-Vandry, room 1323, 1050 avenue de la Médecine, Quebec, QC G1V 0A6, Canada. ${ }^{3}$ Quebec Excellence Centre on Aging, St-Sacrement Hospital, 1050 chemin Ste-Foy, Quebec, QC G1S 4L8, Canada. ${ }^{4}$ Laval University, Pavillon Ferdinand-Vandry, room 4211, 1050 avenue de la Médecine, Quebec, QC G1V 0A6, Canada. ${ }^{5}$ VITAM Research Centre on Sustainable Health, Pavillon Landry-Poulin, Door A-1-2, 2nd floor, Room 2416, 2525 Chemin de la Canardière, Québec, QC G1J OA4, Canada. ${ }^{6}$ VITAM Research Centre on Sustainable Health, Pavillon Landry-Poulin, Door A-1-2, 2525 Chemin de la Canardière, Québec, QC G1J OA4, Canada. ' Quebec Excellence Centre on Aging, St-Sacrement Hospital, Office L-2, 1050 chemin Ste-Foy, Quebec, QC G1S 4L8, Canada. ${ }^{8}$ Pavillon Ferdinand-Vandry, room 3445, 1050 avenue de la Médecine, Quebec, QC G1V 0A6, Canada. 'Department of Family Medicine, McGill University, 5858 chemin de la Côte-des-Neiges, 3rd floor, Montreal, QC H3S 1Z1, Canada. ${ }^{10}$ VITAM Research Centre on Sustainable Health, Pavillon Landry-Poulin, Door A-1-2, 4th floor, Room 4578, 2525 Chemin de la Canardière, Québec, QC G1J OA4, Canada.

Received: 23 March 2020 Accepted: 22 July 2020

Published online: 12 August 2020

\section{References}

1. Stacey D, Legare F, Lewis K, Barry MJ, Bennett CL, Eden KB, et al. Decision aids for people facing health treatment or screening decisions. Cochrane Database Syst Rev. 2017;4:CD001431 https://doi.org/10.1002/14651858. CD001431.pub5.

2. Couet N, Desroches S, Robitaille H, Vaillancourt H, Leblanc A, Turcotte S, et al. Assessments of the extent to which health-care providers involve patients in decision making: a systematic review of studies using the OPTION instrument. Health Expect. 2015;18:542-61.
3. Hanson LC, Zimmerman S, Song M-KK, Lin F-CC, Rosemond C, Carey TS, et al. Effect of the goals of care intervention for advanced dementia: a randomized clinical trial. JAMA Intern Med. 2017;177:24-31 https://doi.org/ 10.1001/jamainternmed.2016.7031.

4. Einterz SF, Gilliam R, Lin FC, McBride JM, Hanson LC. Development and testing of a decision aid on goals of care for advanced dementia. J Am Med Dir Assoc. 2014;15:251-5 https://doi.org/10.1016/j.jamda.2013.11.020.

5. Adekpedjou R, Stacey D, Briere N, Freitas A, Garvelink MM, Dogba MJ, et al. Engaging Caregivers in Health-Related Housing Decisions for Older Adults With Cognitive Impairment: A Cluster Randomized Trial. Gerontologist. 2019: 60(5):947-57 https://academic.oup.com/gerontologist/article/60/5/947/54 90227.

6. Adekpedjou R, Stacey D, Brière N, Freitas A, Garvelink MM, Turcotte S, et al. "Please listen to me": a cross-sectional study of experiences of seniors and their caregivers making housing decisions. PLoS One. 2018;13:1-19.

7. Miller LM, Whitlatch CJ, Lyons KS. Shared decision-making in dementia: a review of patient and family carer involvement. Dement. 2016;15:1141-57.

8. Légaré F, Adekpedjou R, Stacey D, Turcotte S, Kryworuchko J, Graham ID, et al. Interventions for increasing the use of shared decision making by healthcare professionals. Cochrane Database Syst Rev. 2018;7:CD006732 https://doi.org/10.1002/14651858.CD006732.pub4.

9. Diouf NT, Menear M, Robitaille H, Painchaud Guérard G, Légaré F. Training health professionals in shared decision making: update of an international environmental scan. Patient Educ Couns. 2016;99:1753-8.

10. Siyam T, Shahid A, Perram M, Zuna I, Haque F, Herrera MCA, et al. A scoping review of interventions to promote the adoption of shared decision-making (SDM) among health care professionals in clinical practice. Patient Educ Couns. 2019;102:1057-66.

11. Shahhosseini Z, Hamzehgardeshi Z. The facilitators and barriers to nurses' participation in continuing education programs: a mixed method explanatory sequential study. Global J Health Sci. 2014;7:184-93 https://doi. org/10.5539/gjhs.v7n3p184.

12. Allaire AS, Labrecque M, Giguere A, Gagnon MP, Legare F. What motivates family physicians to participate in training programs in shared decision making? J Contin Educ Heal Prof. 2012;32:98-107 https://doi.org/10.1002/ chp.21132.

13. Vaona A, Banzi R, Kwag KH, Rigon G, Cereda D, Pecoraro V, et al. E-learning for health professionals. Cochrane Database Syst Rev. 2018; https://doi.org/ 10.1002/14651858.CD011736.pub2.

14. Legare F, Labrecque M, Cauchon M, Castel J, Turcotte S, Grimshaw J. Training family physicians in shared decision-making to reduce the overuse of antibiotics in acute respiratory infections: a cluster randomized trial. Cmaj. 2012;184:E726-34 https://doi.org/10.1503/cmaj.120568.

15. Poirier A, Voyer $\mathrm{P}$, Légaré $\mathrm{F}$, Morin $\mathrm{M}$, Witteman $\mathrm{HO}$, Kröger E, et al. Caring for seniors living with dementia means caring for their caregivers too. Can J Public Heal. 2018;108:639 https://doi.org/10.17269/cjph.108.6217.

16. Giguere AMC, Labrecque M, Haynes RB, Grad R, Pluye P, Legare F, et al. Evidence summaries (decision boxes) to prepare clinicians for shared decision-making with patients: a mixed methods implementation study. Implement Sci. 2014;9:144.

17. Giguere A, Legare F, Grad R, Pluye P, Haynes RB, Cauchon M, et al. Decision boxes for clinicians to support evidence-based practice and shared decision making: the user experience. Implement Sci. 2012;7:72 https://doi.org/10. 1186/1748-5908-7-72.

18. Bilodeau $G$, Witteman $H O$, Légaré F, Lafontaine-Bruneau J, Voyer $P$, Kröger $E$, et al. Reducing complexity of patient decision aids for community-based older adults with dementia and their caregivers: multiple case study of decision boxes. BMJ Open. 2019;9:e027727.

19. Giguere AMC, Lawani MA, Fortier-Brochu É, Carmichael P-H, Légaré F, Kröger $E$, et al. Tailoring and evaluating an intervention to improve shared decision making among seniors with dementia, their caregivers and healthcare providers: study protocol for a randomized controlled trial. Trials. 2018;19:332 https://doi.org/10.1186/s13063-018-2697-1.

20. Stacey D, Légaré F, Boland L, Lewis KB, Loiselle M-C, Hoefel L, et al. 20th anniversary Ottawa decision support framework: part 3 overview of systematic reviews and updated framework. Med Decis Mak. 2020;40:379-98.

21. Légaré F, Borduas F, Freitas A, Jacques A, Godin G, Luconi F, et al. Development of a simple 12-item theory-based instrument to assess the impact of continuing professional development on clinical behavioral intentions. PLoS One. 2014;9:e91013 https://doi.org/10.1371/journal.pone. 0091013. 
22. Giguere AM, Bogza L-M, Coudert L, Carmichael P-H, Renaud J-S, Légaré F, et al. Development of the IcanSDM scale to assess primary care clinicians' ability to adopt shared decision making. Res Sq. 2020; https://doi.org/10 21203/rs.3.rs-19647/v1.

23. Strull WM, Lo B, Charles G. Do patients want to participate in medical decision making? JAMA. 1984;252:2990-4 https://www.ncbi.nlm.nih.gov/ pubmed/6502860

24. Lawani MA, Turgeon $Y$, Côté $L$, Légaré $F$, Witteman HO, Morin M, et al. Usercentered and theory-based design of a professional training program on shared decision making with older adults living with neurocognitive disorders: a mixed-methods study. Submitt BMC Med Inf Decis Mak.

25. Godin G, Belanger-Gravel A, Eccles M, Grimshaw J. Healthcare professionals' intentions and behaviours: a systematic review of studies based on social cognitive theories. Implement Sci. 2008;3:36 https://doi.org/10.1186/17485908-3-36.

26. Creswell JW. Research design: Qualitative, quantitative, and mixed methods approaches. 4th ed. Thousand Oaks: Sage; 2014.

27. Vasileiou K, Barnett J, Thorpe S, Young T. Characterising and justifying sample size sufficiency in interview-based studies: systematic analysis of qualitative health research over a 15-year period. BMC Med Res Methodol. 2018;18:148.

28. Cook DA, Price DW, Wittich CM, West CP, Blachman MJ. Factors influencing physicians' selection of continuous professional development activities: a cross-specialty National Survey. J Contin Educ Heal Prof. 2017;37:154-60 https://doi.org/10.1097/CEH.0000000000000163.

29. Rosenstiel T, Mitchell A. YouTube \& News: A new kind of visual journalism. Washington (DC): Pew Research Center; 2012. https://www.pewresearch. org/wp-content/uploads/sites/8/2012/07/YouTube-the-News-A-PEJ-ReportFINAL.pdf.

30. Carr S. As distance education comes of age, the challenge is keeping the students. Chron High Educ. 2000;46(23):A39-41.

31. Patterson $B$, McFadden C. Attrition in online and campus degree programs. Online J Distance Learn Adm. 2009;12:1-8.

32. Jeong D, Presseau J, ElChamaa R, Naumann DN, Mascaro C, Luconi F, et al. Barriers and facilitators to self-directed learning in continuing professional development for physicians in Canada: a scoping review. Acad Med. 2018; 93:1245-54 https://doi.org/10.1097/ACM.0000000000002237.

33. Regmi K, Jones L. A systematic review of the factors-enablers and barriersaffecting e-learning in health sciences education. BMC Med Educ. 2020;20: $1-18$.

34. Ellaway R, Masters K. AMEE Guide 32: e-Learning in medical education Part 1: Learning, teaching and assessment. Med Teach. 2008;30:455-73. https:// doi.org/10.1080/01421590802108331.

35. Broadbent J, Poon WL. Self-regulated learning strategies \& academic achievement in online higher education learning environments: A systematic review. Internet High Educ. 2015;27:1-13.

36. Wang C, Hsu H-CK, Bonem EM, Moss JD, Yu S, Nelson DB, et al. Need satisfaction and need dissatisfaction: A comparative study of online and faceto-face learning contexts. Comput Hum Behav. 2019;95:114-25.

37. Kienlin S, Kristiansen M, Ofstad E, Liethmann K, Geiger F, Joranger P, et al. Validation of the Norwegian version of MAPPIN'SDM, an observationbased instrument to measure shared decision-making in clinical encounters. Patient Educ Couns. 2017;100:534-41. https://doi.org/10.1016/j.pec.2016.10.023.

38. Kasper J, Liethmann K, Heesen C, Reissmann DR, Geiger F. Training doctors briefly and in situ to involve their patients in making medical decisions - Preliminary testing of a newly developed module. Health Expect. 2017;20:1254-63. https://doi.org/10.1111/hex.12565.

39. Mamary E, Charles P. Promoting self-directed learning for continuing medical education. Med Teach. 2003;25:188-90 https://acces.bibl.ulaval.ca/ login?url=https://search.ebscohost.com/login.aspx?direct=true\&db= mnh\&AN=12745529\&lang=fr\&site=ehost-live.

40. Gagnon MP, Legare F, Labrecque M, Fremont P, Cauchon M, Desmartis M. Perceived barriers to completing an e-learning program on evidence-based medicine. Inf Prim Care. 2007;15:83-91 http://www.ncbi.n/m.nih.gov/entrez/ query.fcgi?cmd=Retrieve\&db=PubMed\&dopt=Citation\&list_uids=17877870.

41. Smith L, Curry M. Twelve tips for supporting online distance learners on medical post-registration courses. Med Teach. 2005;27:396-400.

42. Giguere AMC, Labrecque M, Légaré F, Grad R, Cauchon M, Greenway M, et al. Feasibility of a randomized controlled trial to evaluate the impact of decision boxes on shared decision-making processes. BMC Med Inform Decis Mak. 2015;15.
43. Giustini D, Ali SM, Fraser M, Boulos MNK. Effective uses of social media in public health and medicine: a systematic review of systematic reviews. Online J Public Health Inform. 2018;10.

44. Hellström I, Nolan M, Nordenfelt L, Lundh U. Ethical and methodological issues in interviewing persons with dementia. Nurs Ethics. 2007;14:608-19.

45. Banzi R, Camaioni P, Tettamanti M, Bertele V, Lucca U. Older patients are still under-represented in clinical trials of Alzheimer's disease. Alzheimers Res Ther. 2016;8:32. https://doi.org/10.1186/s13195-016-0201-2.

46. Bartlett R, Milne R, Croucher R. Strategies to improve recruitment of people with dementia to research studies. Dementia. 2018;18:2494-504. https://doi. org/10.1177/1471301217748503.

\section{Publisher's Note}

Springer Nature remains neutral with regard to jurisdictional claims in published maps and institutional affiliations.

\section{Ready to submit your research? Choose BMC and benefit from:}

- fast, convenient online submission

- thorough peer review by experienced researchers in your field

- rapid publication on acceptance

- support for research data, including large and complex data types

- gold Open Access which fosters wider collaboration and increased citations

- maximum visibility for your research: over $100 \mathrm{M}$ website views per year

At BMC, research is always in progress.

Learn more biomedcentral.com/submissions 